\title{
К ВОПРОСУ О ФОРМЕ ПОБУДИТЕЛЬНОГО ПРЕДЛОЖЕНИЯ
}

Коммуникативные типы предложений, формы выражения различных коммуникативных намерений говорящего - одна из тем современной лингвистики, привлекающих наиболее пристальное внимание ученых. В традиционной грамматике было выработано представление о трех основных коммуникативных типах предложений - повествовательном, вопросительном, побудительном. Причем неоднократно отмечалось, что «несмотря на содержательно ориентированное название типов, эта классификация по существу структурная» [Иванова, 1981: 175]. Эта мысль представляется особенно справедливой по отношению к так называемому побудительному предложению.

Обычно считается, что главная форма выражения побуждения - повелительное наклонение глагола, и, таким образом, «прямая» и основная форма побудительного предложения - это и есть «предложение с глаголом в повелительном наклонении». Однако толкования этой формы различны. Нетрадиционным является мнение, что данная форма (типа Take the book) не относится к наклонению вообще [Гроот, 1972; Гак, 2004]. Действительно, по словарному определению, наклонение - грамматическая категория, выражающая отношение действия, названного глаголом, к действительности с точки зрения говорящего [ЛЭС, 2002: 321]. И если глагол в изъявительном и сослагательном наклонении это отношение несомненно выражает, то глагол в так называемой форме повелительного наклонения не выражает отношения названного действия к действительности, он только выражает побуждение, волеизъявление говорящего, чтобы кто-то это действие совершил. Поэтому «императив не является наклонением по своему значению, ибо «императив вообще не выражает какоголибо факта, который может характеризоваться как реальный или нереальный» [Храковский, 2001: 68]. Императив (так мы будем далее называть обсуждаемую глагольную форму) не связан с сообщением о каких-либо явлениях действительности. Побуждение - особая мысль о желаемом, непосредственное волеизъявление, в то время как сообщение о действии (глаголы в изъявительном или сослагательном наклонениях) обязательно опосредовано соотнесением с действительностью. Сравним: Boys, take the books! и Boys took the books. Императив, относясь к сфере непосредственной коммуникации, является одной из форм побудительного высказывания, в то время как невозможно говорить об «изьявительных» или «сослагательных» высказываниях [Гроот, 1972: 192].

Подобной точки зрения придерживается и Д. А. Штелинг, считая, что категория наклонения свойственна только глагольным формам, выполняющим повествовательную функцию, где имеет место сообщение для кого-то или вопрос кому-то, т.е. там, где действительно происходит двусторонний речевой акт и взаимное речевое общение. А «императив функционирует не как глаголсказуемое, а самостоятельно, образуя особое - побудительное - предложение, и 
относится к сфере непосредственного общения, а не сообщения» [Штелинг, 1996: 49].

Не случайно в исследованиях на материале английского языка утверждается, что на протяжении всей истории императив обнаруживает тенденцию к ослаблению и отмиранию не только как инфинитивная форма, но и как форма наклонения [Ермолаева, 1972: 101-103].

Таким образом, можно отметить, что в содержательном плане ту форму глагола, которая обычно считается формой повелительного наклонения глагола, вряд ли следует причислять к этой грамматической категории. Дж. Лайонз отмечает, что «<..> положение о необходимости различать тип предложения и наклонение имеет не просто терминологическую природу <...> это разграничение может рассматриваться как свидетельство в пользу представления логической структуры предложений и высказываний в виде трёхчастной <..> структуры. Терминология в любом случае особенно важна <..>, поскольку она позволяет нам разделять не только тип предложения и наклонение (которые часто смешиваются даже лингвистами), но также форму и функцию» [Лайонз, 2003: 195]. Следовательно, с одной стороны, специфика императива позволяет изолировать его от категории наклонения: «Можно даже утверждать, что императив и формы наклонений не соизмеримы друг с другом, поскольку выполняют разные языковые функции» [Храковский, 2001: 70].

С другой стороны, возможен и другой путь - расширительное толкование самой категории наклонения, которое бы позволило включить в него императив. Так, М. Я. Блох выдвигает оригинальную точку зрения, считая, что семантика императива вполне соответствует наклонению «нереальности» (в оппозиции к наклонению «реальности»), т.к. данная форма представляет действие не как факт, а как воображаемое (если выразиться конкретнее - желаемое) явление. Сама форма императива полностью совпадает с тем, что по традиции называют устаревшей формой Subjunctive I. Cp.: So be it! God forgive us. It's important that he arrive here as soon as possible. $\sim \underline{B e}$ off! $\underline{\text { Do }}$ as I ask you!

М. Я. Блох предлагает объединить обе формы, назвав их одной формой «наклонения отношений» (mood of attitudes), поскольку, будучи формально идентичными, они выражают различные оттенки семантики «отношения», к которым причисляются как варианты степени выражения желания, предположение, размышление, предложение, рекомендация и др. [Блох, 2000: 182].

Таким образом, если согласиться с тем, что глагол в императиве, выражающий волеизъявление, действительно представляет действие как пока ещё не реальное, но желаемое, и на этом основании воспринимать форму императива как одну из форм категории наклонения нереальности, то необходимо изменить представление и о форме побудительного предложения. Следует отметить, что включение различных побудительных значений в понятие «наклонения отношений» сильно расширяет толкование наклонения, включая в него коммуникативное намерение говорящего, а не только «отношение высказывания к действительности» (по традиционному определению). В такой расширительной трактовке «<..> наклонение лучше всего может быть определено как 
категория, которая возникает в результате грамматикализации субъективной модальности и других видов экспрессивного значения, включая некоторую часть того, что в настоящее время обычно называется иллокутивной силой» [Лайонз, 2003: 195].

Продолжая разговор об этой форме, которую Дж. Керм называет «старой формой императива» (Hurry up! Speak!), подчеркнём, что она идентична форме 2 лица изъявительного наклонения Present Indefinite и является грамматическим омонимом этой формы. Данные формы, имея одинаковый вид, различаются значением и употреблением. Форма глагола 2 лица изъявительного наклонения Present Indefinite используется в коммуникативном плане для передачи таких речевых действий как сообщение, констатация, утверждение, и является частью предикативного ядра утвердительного предложения (сказуемым) по своему грамматико-синтаксическому статусу. Форма императива используется в коммуникативном плане для выражения приказа, команды, просьбы, мольбы, совета, запрета. В грамматико-синтаксическом плане она не является частью предикативного ядра (сказуемым), т.к. функционирует самостоятельно, поскольку эксплицитного выражения адресата при непосредственном волеизъявлении обычно не требуется - он ясен из ситуации общения - это всегда тот, к кому непосредственно обращается говорящий.

Описывая эти структурно-синтаксические отличия, А. И. Смирницкий писал: «Предикативная связь не является заранее данной, заранее известной - в сказуемом признак вводится как некое открытие, как то, что приписывается предмету. В императиве же мысль об адресате уже заранее дана в самой форме императива, имплицирована в ней» [Смирницкий, 1959: 345].

И всё же совсем не случайно форма императива совпадает с формой 2 лица индикатива - внутренне все перечисленные иллокутивные акты: и сообщение, констатация, утверждение с одной стороны, и приказ, просьба, совет и т.д. с другой стороны, предполагают адресата, два или несколько участников коммуникации. И в том, и в другом случае имеет место обращение к слушающему, но с разными намерениями. В случае обращения с намерениями сообщения, констатации и т.п. используются двусоставные повествовательные предложения с глаголом в индикативе. В случае обращения с намерением побуждения к действию (в широком смысле) может использоваться односоставное предложение с формой императива (омонимичного индикативу 2 лица Present Indefinite).

Вот это односоставное предложение с глаголом-императивом и считается таким образом «прямой» и главной формой выражения побуждения. Подводя итог замечаниям по поводу этой формы, хотелось бы остановиться на проблеме терминологии. Предложения, о которых шла речь (Go. Shut the door! Speak! Take the book, please.), в лингвистической литературе называют побудительными, противопоставляя их повествовательным и вопросительным. Но дело в том, что в случае повествовательных и вопросительных предложений имеется чёткая корреляция формы и содержания в названии. Действительно, форма повествовательного предложения - основная форма для выражения повествования 
как коммуникативного намерения в разных его видах (сообщение, констатация и т.п.). Форма вопросительного предложения - основная форма для выражения запроса информации в качестве коммуникативного намерения. Другие формы для выражения этих коммуникативных намерений достаточно редки и являются косвенными, вторичными, становятся результатом транспонирования при обычной их полиинтенциональности, т.е., в частности, сохранении изначального коммуникативного намерения наряду с косвенным. Совершенно другое положение имеет место в случае так называемых побудительных предложений. С формально-структурной точки зрений было бы точнее назвать их односоставными предложениями с императивом (не называя его глаголом в повелительном наклонении, поскольку, как мы попытались показать, эта форма не всегда признаётся формой наклонения, либо может быть представлена как форма наклонения отношения как подвида наклонения нереальности). Такие предложения, конечно, выражают коммуникативные намерения побуждения, но не являются главной формой выражения побуждения. Различные варианты этого коммуникативного намерения (приказ, команда, совет, просьба и т.п.) гораздо чаще, чем это отмечается, выражаются повествовательными и вопросительными по форме предложениями. Причём коммуникативное намерение побуждения является в этих случаях единственным их назначением, а не косвенным, вторичным, как это происходит при транспонировании. И если термин «побудительное высказывание» является содержательным и предполагает многие формы, то выражение «побудительное предложение» обычно означает только одну форму - односоставное предложение с императивом.

$$
* * *
$$

БЛОХ М. Я. Теоретическая грамматика английского языка. М., 2000

ГАК В. Г. Теоретическая грамматика французского языка. М., 2004

ГРООТ А. В. Классификация групп слов // Принципы типологического анализа языков различного строя. М., 1972

ЕРМОЛАЕВА Л. С. Типология системы наклонения в современных германских языках // Вопросы языкознания. № 4. М., 1972

ИВАНОВА И. П., Бурлакова В. В., Почепцов Г. Г. Теоретическая грамматика современного английского языка. М., 1981

ЛАЙОНЗ Дж. Лингвистическая семантика. Введение. М., 2003

ЛИНГВИСТИЧЕСКИЙ энциклопедический словарь (под ред. В. Н. Ярцевой). М., 2002

СМИРНИЦКИЙ А. И. Морфология английского языка. М., 1959

ХРАКОВСКИЙ В. С., Володин А. П. Семантика и типология императива. М., 2001

ШТЕЛИНГ Д. А. Грамматическая семантика английского языка. Фактор человека в языке. М., 1996 


\section{АННОТАЦИЯ}

статьи Г. Г. Сёмкиной «К вопросу о форме побудительного предложения».

В статье рассматриваются вопросы соотношения содержательных и формальных признаков в побудительном предложении. Анализируются возможные толкования формы побудительного предложения. Обсуждается проблема повелительного наклонения в английском языке. Уточняются понятия побудительного предложения и побудительного высказывания. 
Сведения об авторе

Сёмкина Галина Григорьевна

Место работы - ОмГУ

Домашний адрес - Омск 644010

пр. Маркса, 10 - 20

д.т. $51-01-92$

e-mail: gsemkina@yandex.ru

Паспорт серия 5204 номер 875105 выдан УВД № 1 ЦАО г. Омска 30.01.2004

ИНН 550402798321

№ пенсионного страхового свидетельства 057 - 865 - 059 - 04 